\title{
Low Cognitive Ability in Subjects With Bronchiectasis
}

\author{
Pınar Yıldız Gülhan MD, Emel Bulcun MD, Mustafa Gülhan MD, Dilay Çimen MD, \\ Aydanur Ekici MD, and Mehmet Ekici MD
}

\begin{abstract}
BACKGROUND: Bronchiectasis may change cognitive function. The mechanism responsible for cognitive dysfunction in COPD may be neuronal damage caused by hypoxia. Cognitive function in patients with bronchiectasis is also likely to be affected by similar mechanisms. The goal of this study was to determine the frequency and determinants of low cognitive ability in subjects with stable bronchiectasis. METHODS: Thirty subjects with stable bronchiectasis and 25 healthy volunteers underwent a cognitive ability assessment using the Wechsler Adult Intelligence Scale. Bronchiectasis was diagnosed by high-resolution computed tomography of the chest. Age, body mass index, the Hospital Anxiety and Depression Scale, and pulmonary function were assessed. Perceived intensity of dyspnea after exercise (after climbing 3 flights of stairs) was estimated using a modified Borg scale. RESULTS: Mean scores on the verbal and performance tests and full-scale IQ scores were significantly lower in subjects with bronchiectasis than in healthy volunteers. Low cognitive ability in subjects with bronchiectasis was associated with higher depression scores, lower oxygen saturation, and poor lung function after adjusting for potential confounders in multivariate analysis. Borg scores after exercise in subjects with bronchiectasis and low cognitive ability were higher than those in subjects with bronchiectasis and high cognitive ability, despite similar $\mathrm{P}_{a O_{2}}$ and FEV $_{1}$ in both groups. CONCLUSIONS: Low cognitive ability in subjects with bronchiectasis may be associated with reduced lung function, more serious hypoxemia, and higher depressive symptoms. Subjects with bronchiectasis and low cognitive ability feel more intense dyspnea than do those with high cognitive ability. Key words: cognitive ability; bronchiectasis; hypoxemia; lung functions. [Respir Care 2015;60(11):1610-1615. (C) 2015 Daedalus Enterprises]
\end{abstract}

\section{Introduction}

Bronchiectasis is being increasingly diagnosed in adults due to the more widespread availability of high-resolution computed tomography. ${ }^{1,2}$ Bronchiectasis can develop as a

Drs PY Gülhan, Bulcun, Çimen, A Ekici, and M Ekici are affiliated with the Department of Pulmonary Diseases, and Dr M Gülhan is affiliated with the Department of Infectious Diseases, Faculty of Medicine, Kırıkkale University, Kırıkkale, Turkey.

Presented at the 24th European Respiratory Society (ERS) Annual Congress, September 6-10, 2014, Munich, Germany.

The authors have disclosed no conflicts of interest.

Correspondence: Emel Bulcun MD, Department of Pulmonary Disease, Faculty of Medicine, Kırıkkale University, 71100 Kırıkkale, Turkey. E-mail: emelbulcun@hotmail.com.

DOI: $10.4187 /$ respcare.03905 result of different airway insults and is a chronic infective and inflammatory respiratory disease that causes significant morbidity and mortality. ${ }^{3-6}$ Bronchiectasis may cause pulmonary infections and loss of lung function. ${ }^{7}$ Despite infection playing an important role in the underlying etiology, no cause can be found in a significant proportion of cases. ${ }^{8-10}$ However, increased susceptibility to respiratory tract infections or chronically inflamed airways can facilitate the development of bronchiectasis. ${ }^{11,12}$

Bronchiectasis may change cognitive function, and studies evaluating this variable in subjects with bronchiectasis are insufficient. Hypoxia may adversely affect cognitive function, particularly in patients with chronic cardiac pulmonary failure. ${ }^{13}$ The exact relationship between cognitive impairment and hypoxemia remains unclear. The mechanism responsible for cognitive dysfunction in COPD may be neuronal damage caused by hypoxia. ${ }^{14}$ Cognitive functions in patients with bronchiectasis are also likely to be affected by similar mechanisms. 
Patients with bronchiectasis may have associated low cognitive ability. The goal of this study was to determine the frequency and determinants of low cognitive ability in subjects with stable bronchiectasis.

\section{Methods}

Consecutive patients diagnosed with bronchiectasis, admitted to the out-patient clinic in the Department of Chest Disease at Kırıkkale University between August 2013 and December 2013, were included in this study. Twenty-five age- and sex-matched healthy older adults were recruited from the visitors accompanying the subjects. All subjects signed informed consent forms, and the study was approved by the local ethics committee.

Exclusion criteria included: cardiac disorders, cognitive impairment, treatment with systemic corticosteroids, and respiratory tract infection in the previous 4 weeks. A detailed history, physical examination, and spirometric measurements were obtained from each subject. Subjects taking drugs, such as benzodiazepine, that affect cognitive function were not included this study. Body mass index was calculated by measuring weight and height. Arterial blood gases were taken from subjects with stable bronchiectasis. Arterial blood gases were measured by arterial puncture in the morning while subjects were seated (15 min) and breathing room air for at least $45 \mathrm{~min}$. Bronchiectasis was diagnosed by high-resolution computed tomography of the chest, with 1-mm slices at $10-\mathrm{mm}$ intervals in deep inspiration, according to the criteria of Naidich et al. ${ }^{15}$

Perceived intensity of dyspnea after exercise (after climbing 3 flights of stairs) was estimated using a modified Borg scale, ranging from 0 (no symptoms) to 10 (maximum bearable). ${ }^{16}$ Subjects were first asked to score how dyspneic they felt using the Borg scale.

\section{Wechsler Adult Intelligence Scale-Revised}

The Wechsler Adult Intelligence Scale battery (17) consists of 11 diverse subtests that measure a variety of verbal and non-verbal mental abilities that contribute to general intelligence ( $\mathrm{g}$ factor). The Wechsler Adult Intelligence Scale full-scale IQ score is based on performance on all 11 subtests. The Wechsler Adult Intelligence Scale-Revised consists of 6 verbal subtests and 5 performance subtests. The verbal tests are: information, comprehension, arithmetic, digit span, similarities, and vocabulary. However, in this study, we did not evaluate vocabulary. The performance subtests were: picture arrangement, picture completion, block design, object assembly, and digit symbol. The scores derived from this test are verbal, performance, and full-scale IQs. The subtests have a mean \pm SD of $10 \pm 3$; the full-scale, verbal, and performance IQ scores

\section{QUICK LOOK}

\section{Current knowledge}

Bronchiectasis is a frequent comorbidity in COPD. Bronchiectasis can develop as a result of multiple airway insults creating a chronic infective and inflammatory respiratory process that causes significant morbidity and mortality. Bronchiectasis is also associated with pulmonary infections and loss of lung function. Hypoxemia is a common symptom with a number of attendant consequences.

\section{What this paper contributes to our knowledge}

Low cognitive ability in subjects with bronchiectasis was associated with reduced lung function, more serious hypoxemia, and greater depressive symptoms. Subjects with bronchiectasis and low cognitive ability felt more intense dyspnea than did those with high cognitive ability.

have a mean $\pm \mathrm{SD}$ of $100 \pm 15 \cdot{ }^{17,18}$ The test has been adapted and validated for use in the Turkish population. ${ }^{19}$ The revised form was published in $1981 .{ }^{17}$

The test was taken in quiet surroundings, and all subjects underwent a brief psychological interview beforehand; special care was taken to minimize potential anxiety regarding test performance. Moreover, it was clearly stated at the time of inclusion that test results would in no case be linked to any care change for subjects or to any specific psychological intervention. Subjective scoring of the Wechsler Adult Intelligence Scale-Revised was conducted with blinding to the subjects' study group.

The median full-scale IQ score was accepted as the cutoff point. High cognitive ability was defined as a score above the cutoff point (median 83.5). Accordingly, high cognitive ability was described as a full-scale IQ score of $>83.5$. Low cognitive ability was described as a full-scale IQ score of $<83.5$.

\section{Assessment of Psychological Status}

Participants were asked to fill in the self-reported Hospital Anxiety and Depression Scale questionnaire for the assessment of psychological distress. The questionnaire consisted of 14 questions in which the overall severity of anxiety and depression was rated on a 4-point scale (0-3). Seven questions were related to anxiety and 7 to depression. ${ }^{20}$ We used the Turkish version of the Hospital Anxiety and Depression Scale. The Turkish version of the Hospital Anxiety and Depression Scale questionnaire has been validated in Turkey by Aydemir et al. ${ }^{21}$ 


\section{Cognitive Ability and Bronchiectasis}

Table 1. Characteristics of the Control Group and Subjects With Bronchiectasis

\begin{tabular}{lccc}
\hline \hline \multicolumn{1}{c}{ Characteristic } & $\begin{array}{c}\text { Bronchiectasis } \\
\text { Group } \\
(n=30)\end{array}$ & $\begin{array}{c}\text { Control } \\
\text { Group } \\
(n=25)\end{array}$ & $P$ \\
\hline Age, mean $\pm \mathrm{SD}$ y & $45.4 \pm 14.1$ & $41.4 \pm 12.7$ & .2 \\
Females/males, $n$ & $18 / 12$ & $9 / 16$ & .07 \\
BMI, mean $\pm \mathrm{SD} \mathrm{kg} / \mathrm{m}^{2}$ & $27.4 \pm 5.9$ & $27.7 \pm 4.1$ & .8 \\
Education level, mean $\pm \mathrm{SD}$ & $1.9 \pm 0.9$ & $2.8 \pm 1.2$ & .002 \\
$\mathrm{FEV}_{1}$, mean $\pm \mathrm{SD} \%$ predicted & $72.7 \pm 20.8$ & $100.8 \pm 10.9$ & $<.001$ \\
$\mathrm{FEV}_{1} / \mathrm{FVC}$, mean $\pm \mathrm{SD}$ & $74.6 \pm 11.1$ & $85.6 \pm 7.6$ & $<.001$ \\
Depression score, mean $\pm \mathrm{SD}$ & $8.6 \pm 4.4$ & $6.1 \pm 4.0$ & .03 \\
Anxiety score, mean $\pm \mathrm{SD}$ & $9.7 \pm 5.3$ & $6.4 \pm 4.5$ & .01 \\
Borg score after exercise, & $5.4 \pm 1.8$ & $1.2 \pm 1.8$ & $<.001$ \\
$\quad$ mean $\pm \mathrm{SD}$ & & & \\
& & & \\
\hline Statistical significance was $P<.05$ & & & \\
BMI $=$ body mass index & & & \\
\hline
\end{tabular}

\section{Statistical Analysis}

All clinical parameters were expressed as mean \pm SD. Education level was classified as none (1), primary school (2), secondary school (3), or high school (4). Student $t$ and Mann-Whitney tests were performed to assess group differences in continuous data. Categorical variables were compared using chi-square tests. Bivariate analyses were performed using Pearson correlation. Multiple stepwise linear regression was performed to determine the relative contribution of possible confounding factors to cognitive function tests. $P<.05$ was considered to be statistically significant.

\section{Results}

Thirty subjects with bronchiectasis (mean age 45.4 y) and 25 healthy volunteers (mean age 41.4 y) were enrolled. Subjects with bronchiectasis had a lower FEV $\mathrm{F}_{1}$ and higher anxiety and depression scores than healthy volunteers (Table 1). Subjects with bronchiectasis had a lower educational level than healthy volunteers.

Mean scores on the verbal, performance, and full-scale IQs were significantly lower in subjects with bronchiectasis than in healthy volunteers $(87.5 \pm 16.3$ vs $105.8 \pm$ $16.1, P<.001)$. Mean scores on the similarities, information, digit span, arithmetic, digit symbol, picture completion, picture arrangement, block design, object assembly, and comprehension IQ were significantly lower in subjects with bronchiectasis than in healthy volunteers (Table 2). Borg scores after exercise in subjects with bronchiectasis and low cognitive ability were higher than those in subjects with bronchiectasis and high cognitive ability despite the fact that $\mathrm{P}_{\mathrm{aO}}$ and pulmonary function in both groups
Table 2. Subtest Scores and Composite Scores of the Control Group and Subjects With Bronchiectasis

\begin{tabular}{lccr}
\hline \hline \multicolumn{1}{c}{ Test } & $\begin{array}{c}\text { Bronchiectasis } \\
\text { Group } \\
(n=30)\end{array}$ & $\begin{array}{c}\text { Control } \\
\text { Group } \\
(n=25)\end{array}$ & $P$ \\
\hline Full-scale IQ & $87.5 \pm 16.3$ & $106.1 \pm 18.8$ & $<.001$ \\
Verbal IQ & $89.1 \pm 18.4$ & $105.3 \pm 18.4$ & .002 \\
Performance IQ & $87.1 \pm 13.8$ & $105.2 \pm 18.0$ & $<.001$ \\
Similarities & $7.4 \pm 2.5$ & $9.6 \pm 2.2$ & .004 \\
Information & $6.3 \pm 2.6$ & $9.5 \pm 1.9$ & $<.001$ \\
Digit span & $7.3 \pm 2.6$ & $9.1 \pm 2.9$ & .03 \\
Arithmetic & $6.1 \pm 2.4$ & $9.8 \pm 2.4$ & $<.001$ \\
Digit symbol & $6.4 \pm 2.3$ & $8.9 \pm 2.2$ & .001 \\
Picture completion & $6.6 \pm 2.6$ & $9.4 \pm 1.9$ & $<.001$ \\
Picture arrangement & $5.5 \pm 2.9$ & $9.6 \pm 3.1$ & $<.001$ \\
Block design & $4.9 \pm 2.3$ & $7.3 \pm 1.9$ & .001 \\
Object assembly & $8.01 \pm 2.2$ & $10.2 \pm 1.7$ & .001 \\
Comprehension & $7.2 \pm 2.6$ & $9.4 \pm 2.1$ & .002 \\
\end{tabular}

Data are mean $\pm \mathrm{SD}$. Statistical significance of $P<.05$. Ten subtest scores: each with mean $=10, \mathrm{SD}=3$. Three composite scores: verbal, performance, full-scale, each with mean $=100, \mathrm{SD}=15$.

Table 3. Characteristics of Subjects With Bronchiectasis With High and Low Cognitive Ability

\begin{tabular}{|c|c|c|c|}
\hline \multirow[b]{2}{*}{ Characteristic } & \multicolumn{3}{|c|}{ Full-Scale IQ } \\
\hline & $\begin{array}{c}\text { Subjects with } \\
\text { bronchiectasis } \\
\text { and low cognitive } \\
\text { ability }(n=15)\end{array}$ & $\begin{array}{c}\text { Subjects with } \\
\text { bronchiectasis } \\
\text { and high cognitive } \\
\text { ability }(n=15)\end{array}$ & $P$ \\
\hline Age, mean \pm SD y & $49.4 \pm 12.3$ & $41.5 \pm 15.1$ & .1 \\
\hline Females/males, $n$ & $3 / 12$ & $9 / 6$ & .06 \\
\hline $\begin{array}{l}\text { Education level, } \\
\text { mean } \pm \mathrm{SD}\end{array}$ & $1.3 \pm 0.8$ & $2.5 \pm 0.6$ & .001 \\
\hline $\mathrm{BMI}$, mean $\pm \mathrm{SD} \mathrm{kg} / \mathrm{m}^{2}$ & $29.9 \pm 5.7$ & $24.9 \pm 5.1$ & .01 \\
\hline $\begin{array}{l}\text { Borg score after exercise, } \\
\text { mean } \pm \mathrm{SD}\end{array}$ & $6.2 \pm 1.8$ & $4.6 \pm 1.5$ & .01 \\
\hline $\mathrm{P}_{\mathrm{aO}_{2}}$, mean $\pm \mathrm{SD} \mathrm{mm} \mathrm{Hg}$ & $75.1 \pm 10.6$ & $80.7 \pm 7.9$ & .1 \\
\hline $\mathrm{S}_{\mathrm{aO}_{2}}$, mean $\pm \mathrm{SD} \%$ & $94.6 \pm 1.7$ & $95.6 \pm 1.3$ & .08 \\
\hline $\begin{array}{l}\mathrm{FEV}_{1} \text {, mean } \pm \mathrm{SD} \% \\
\text { predicted }\end{array}$ & $72.1 \pm 17.8$ & $73.4 \pm 24.1$ & .8 \\
\hline $\begin{array}{l}\text { Statistical significance of } P<.05 . \\
\mathrm{BMI}_{\mathrm{BM}} \text { body mass index } \\
\mathrm{S}_{\mathrm{aO}_{2}}=\text { arterial oxygen saturation }\end{array}$ & & & \\
\hline
\end{tabular}

were similar $(6.2 \pm 1.8$ vs $4.6 \pm 1.5, P=.01)$ (Table 3$)$. There was a negative relationship of age, anxiety, and depression scores with full-scale IQ scores, whereas there was a positive relationship of oxygen saturation and body mass index with full-scale IQ scores (Table 4).

Full-scale IQ scores in subjects with bronchiectasis were negatively associated with depression scores and positively associated with lung function after adjusting for potential confounders in multivariate analysis. Full-scale IQ scores 


\section{Cognitive Ability and Bronchiectasis}

Table 4. Simple Correlation Between Cognitive Ability and Study Variables in Subjects With Bronchiectasis

\begin{tabular}{|c|c|c|c|c|c|c|c|c|c|c|c|c|c|c|}
\hline \multirow[t]{2}{*}{ Test } & \multicolumn{2}{|c|}{ Age } & \multicolumn{2}{|c|}{ BMI } & \multicolumn{2}{|c|}{ Depression Score } & \multicolumn{2}{|c|}{ Anxiety Score } & \multicolumn{2}{|c|}{$\begin{array}{c}\% \\
\text { Predicted } \\
\mathrm{FEV}_{1} \\
\end{array}$} & \multicolumn{2}{|c|}{$\mathrm{S}_{\mathrm{aO}_{2}}$} & \multicolumn{2}{|c|}{$\mathrm{P}_{\mathrm{aO}_{2}}$} \\
\hline & $\mathrm{r}$ & $P$ & $\mathrm{r}$ & $P$ & $\mathrm{r}$ & $P$ & $\mathrm{r}$ & $P$ & $\mathrm{r}$ & $P$ & $\mathrm{r}$ & $P$ & $\mathrm{r}$ & $P$ \\
\hline Full-scale IQ & -0.41 & .002 & 0.39 & .004 & -0.50 & $<.001$ & -0.47 & $<.001$ & 0.17 & .2 & 0.53 & .003 & 0.48 & .008 \\
\hline Verbal IQ & -0.38 & .005 & 0.29 & .03 & -0.40 & .003 & -0.46 & $<.001$ & 0.05 & .7 & 0.47 & .009 & 0.44 & .01 \\
\hline Performance IQ & -0.38 & .005 & 0.29 & .03 & -0.40 & .003 & -0.47 & $<.001$ & 0.05 & .7 & 0.48 & .008 & 0.43 & .02 \\
\hline \multicolumn{15}{|c|}{$\begin{array}{l}\text { Statistical significance of } P<.05 . \\
\mathrm{BMI}=\text { body mass index } \\
\mathrm{S}_{\mathrm{aO}_{2}}=\text { arterial oxygen saturation }\end{array}$} \\
\hline
\end{tabular}

Table 5. Relationship Between Cognitive Ability, Measured by the Wechsler Adult Intelligence Scale-Revised as the Dependent Variable, and Percent-of-Predicted $\mathrm{FEV}_{1}$ and Resting $\mathrm{S}_{\mathrm{aO}_{2}}$ as Independent Variables in Subjects With Bronchiectasis in a Multivariate Model

\begin{tabular}{|c|c|c|c|c|}
\hline \multirow{3}{*}{ Variable } & \multicolumn{4}{|c|}{ Full-Scale IQ Score } \\
\hline & \multicolumn{2}{|c|}{$r^{2}=0.64$} & \multicolumn{2}{|c|}{$r^{2}=0.59$} \\
\hline & $\beta$ & $P$ & $\beta$ & $P$ \\
\hline Intercept & & .001 & & $<.001$ \\
\hline Age & -0.12 & .3 & 0.06 & .6 \\
\hline Male & -0.02 & .8 & -0.10 & .4 \\
\hline Education & 0.51 & .001 & 0.48 & .002 \\
\hline BMI & -0.13 & .3 & -0.09 & .5 \\
\hline Depressive symptoms & -0.38 & .009 & -0.27 & .05 \\
\hline$\%$ predicted $\mathrm{FEV}_{1}$ & 0.25 & .04 & & \\
\hline $\mathrm{S}_{\mathrm{aO}_{2}}$ & & & 0.27 & .03 \\
\hline Smoking & -0.17 & .1 & -0.11 & .3 \\
\hline \multicolumn{5}{|c|}{$\begin{array}{l}\beta \text { is the standardized regression coefficient. Statistical significance of } P<.05 \text {. } \\
\mathrm{BMI}=\text { body mass index } \\
\mathrm{S}_{\mathrm{aO} 2}=\text { arterial oxygen saturation }\end{array}$} \\
\hline
\end{tabular}

in subjects with bronchiectasis were positively associated with oxygen saturation after adjusting for potential confounders in multivariate analysis. Furthermore, age, sex and smoking were not associated with full-scale IQ (Table 5).

\section{Discussion}

Our results indicate that cognitive ability was lower in subjects with bronchiectasis. In addition, low cognitive ability in subjects with bronchiectasis was associated with poorer lung function, lower oxygen saturation, and higher depressive symptoms. The lower educational level in subjects with bronchiectasis compared with the control group could have played a role in this diversity. However, in a multivariate analysis independent of the effect of educational level, hypoxemia, pulmonary function, and depres- sive symptoms determined low cognitive functions. Furthermore, despite similar clinical parameters between the 2 groups, subjects with bronchiectasis and low cognitive ability indicated more intense dyspnea than subjects with high cognitive ability. However, the mechanisms of the relationship between cognitive ability and dyspnea should be explained with further studies. To our knowledge, this is the first study evaluating cognitive ability in subjects with bronchiectasis.

According to the present data, better lung function in subjects with bronchiectasis was associated with better cognitive ability. We had to discuss the results of partially related studies due to the lack of research related to cognitive ability in subjects with bronchiectasis. However, previous studies on the relationship between cognitive function and pulmonary function have yielded conflicting results. A population-based study suggested that lower pulmonary function is associated with subclinical cerebral abnormalities, such as cerebral infarction and white matter lesions, identified by magnetic resonance imaging. ${ }^{22}$ In a study on associations between $\mathrm{FEV}_{1}$ and cognitive function in the British 1946 birth cohort, cognitive function was positively associated with $\mathrm{FEV}_{1}$ across the life course. ${ }^{23}$ In a study in elderly Japanese-American men, low pulmonary function at baseline was associated with cognitive function impairment at least 23 y later. ${ }^{24}$ In another study, childhood IQ was significantly related to $\mathrm{FEV}_{1}$ at age $79 .{ }^{25}$ On the other hand, studies investigating the relationship between lung function and cognition in COPD populations have shown different results, suggesting that lung function cannot sufficiently determine cognitive function in this group. ${ }^{14}$ In this study, age negatively correlated with all cognitive function components according to the Pearson correlation analysis, but no significant association was detected between age and full-scale IQ in linear regression analysis in subjects with bronchiectasis. In addition, sex was not associated with full-scale IQ. Age-related declines in cognitive function in chronic respiratory disease, such as COPD, were found. ${ }^{26}$ However, the mean age of subjects with chronic respiratory disease such as 
COPD was generally higher than mean age of patients with bronchiectasis in our study.

Our study found that hypoxia can cause unfavorable alterations in cognitive ability in subjects with bronchiectasis. Hypoxia may adversely affect cognitive function in patients with cardiac pulmonary failure. ${ }^{13}$ The incidence of cognitive dysfunction is higher in COPD patients with hypoxemia. ${ }^{27}$ Low baseline oxygen saturation in patients with COPD was related to increased risk of cognitive impairment. ${ }^{28}$ In a study evaluating cognitive function with the P300 test in subjects with COPD , P300 latency correlated significantly with $\mathrm{P}_{\mathrm{aO}}, \mathrm{FEV}_{1}$, and age. ${ }^{29} \mathrm{In}$ another study evaluating 203 subjects with COPD, there was a significant inverse correlation between neuropsychological impairment and $\mathrm{P}_{\mathrm{aO}} \cdot{ }^{30}$ The authors concluded that cerebral disturbance may be partly related to a decrease in oxygen use by the brain. Research on cognitive function assessed by single-photon-emission computed tomography in subjects with COPD indicated that worsening of hypoxemia may be associated with frontal-type cognitive decline. ${ }^{31}$ However, current evidence would suggest that hypoxemia alone is not enough to account for the cognitive impairment in COPD. ${ }^{14}$

Depressive symptoms in the subjects with bronchiectasis may be an important determinant for low cognitive ability in the present study. A study with 35 elderly women indicated that the cognitive dysfunction was associated with depressive symptoms. ${ }^{32}$ In another cohort study, depression accompanied cognitive impairment but did not precede it. ${ }^{33}$ In a study evaluating 836 community-dwelling subjects $\geq 70 \mathrm{y}$ of age, higher depressive symptom scores were associated with poorer initial performance in processing speed, verbal fluency, and episodic memory. ${ }^{34}$ In a study in adults 70-90 y of age, individuals with mild cognitive impairment indicated more depressive symptoms compared with mentally healthy individuals. ${ }^{35}$ Another study with 201 elderly subjects admitted to nursing homes showed that depressive symptoms were associated with progressive cognitive decline. ${ }^{36}$ In a meta-analysis of longitudinal studies, subjects with depression had a higher incidence of mild cognitive impairment than those without depression. ${ }^{37}$ According to the authors, depression was a major risk factor for increased incidence of mild cognitive impairment. Depression and cognitive dysfunction share a general neuropathological tract in cortical and subcortical brain areas involved in emotional and cognitive processing. ${ }^{38}$

This study has several limitations. Because the Wechsler Adult Intelligence Scale-Revised test is quite time-consuming and difficult, we include only a small number of subjects with bronchiectasis. In addition, healthy volunteers were also evaluated with these tests. However, in our study, statistically significant and important values were observed.

\section{Conclusions}

In summary, cognitive ability was lower in subjects with bronchiectasis. This impairment may be partly related to poorer lung function, lower oxygen saturation, and higher depressive symptoms. Intervention for these factors in the treatment of patients with bronchiectasis may result in better cognitive ability. Although they have similar clinical parameters, subjects with bronchiectasis and low cognitive ability perceive more severe dyspnea than do subjects with high cognitive ability.

\section{ACKNOWLEDGMENTS}

We thank Omer Oğuzturk PhD for his contribution to the Wechsler Adult Intelligence Scale-Revised.

\section{REFERENCES}

1. Chang AB, Grimwood K, Wilson AC, van Asperen PP, Byrnes CA, O'Grady KA, et al. Bronchiectasis exacerbation study on azithromycin and amoxycillin-clavulanate for respiratory exacerbations in children (BEST-2): study protocol for a randomized controlled trial. Trials 2013;14:53.

2. Yap VL, Metersky ML. Reversible bronchiectasis in an adult: a case report. J Bronchology Interv Pulmonol 2012;19(4):336-337.

3. Anwar GA, McDonnell MJ, Worthy SA, Bourke SC, Afolabi G, Lordan J, et al. Phenotyping adults with non-cystic fibrosis bronchiectasis: a prospective observational cohort study. Respir Med 2013; 107(7):1001-1007.

4. Bartley J, Garrett J, Grant CC, Camargo CA Jr. Could vitamin D have a potential anti-inflammatory and anti-infective role in bronchiectasis? Curr Infect Dis Rep 2013;15(2):148-157.

5. King PT, Holdsworth SR, Farmer M, Freezer NJ, Holmes PW. Chest pain and exacerbations of bronchiectasis. Int J Gen Med 2012;5: 1019-1024.

6. Daheshia M, Prahl JD, Carmichael JJ, Parrish JS, Seda G. The immune response and its therapeutic modulation in bronchiectasis. Pulm Med 2012;2012:280528.

7. Olveira C, Olveira G, Gaspar I, Dorado A, Cruz I, Soriguer F, et al. Depression and anxiety symptoms in bronchiectasis: associations with health-related quality of life. Qual Life Res 2013;22(3):597605 .

8. Bergin DA, Hurley K, Mehta A, Cox S, Ryan D, O’Neill SJ, et al. Airway inflammatory markers in individuals with cystic fibrosis and non-cystic fibrosis bronchiectasis. J Inflamm Res 2013;6:1-11.

9. Boyton RJ, Reynolds CJ, Quigley KJ, Altmann DM. Immune mechanisms and the impact of the disrupted lung microbiome in chronic bacterial lung infection and bronchiectasis. Clin Exp Immunol 2013; 171(2):117-123.

10. Chalmers JD, Hill AT. Mechanisms of immune dysfunction and bacterial persistence in non-cystic fibrosis bronchiectasis. Mol Immunol 2013;55(1):27-34.

11. Truong $\mathrm{T}$. The overlap of bronchiectasis and immunodeficiency with asthma. Immunol Allergy Clin North Am 2013;33(1):61-78.

12. Boyton RJ, Altmann DM. Immune regulation in idiopathic bronchiectasis. Ann N Y Acad Sci 2012;1272:68-72.

13. Gibson GE, Pulsinelli W, Blass JP, Duffy TE. Brain dysfunction in mild to moderate hypoxia. Am J Med 1981;70(6):1247-1254.

14. Dodd JW, Getov SV, Jones PW. Cognitive function in COPD. Eur Respir J 2010;35(4):913-922. 


\section{Cognitive Ability and Bronchiectasis}

15. Naidich DP, McCauley DI, Khouri NF, Stitik FP, Siegelman SS. Computed tomography of bronchiectasis. J Comput Assist Tomogr 1982;6(3):437-444.

16. Wilson RC, Jones PW. A comparison of the visual analogue scale and modified Borg scale for the measurement of dyspnoea during exercise. Clin Sci 1989;76(3):277-282.

17. Wechsler D. WAIS-R manual: Wechsler Adult Intelligence ScaleRevised. New York, New York: The Psychological Corporation; 1981.

18. Wechsler D. Manual for the Wechsler Adult Intelligence Scale. New York, New York: The Psychological Corporation; 1955.

19. Epir S, İskit Ü. The preliminary analysis of the Wechsler Adult Intelligence Scale Turkish translation and potential applications in university counseling centers. Hacettepe Sosyal Bilimler Derg 1972; 4:198-205. Article in Turkish.

20. Zigmond AS, Snaith RP. The hospital anxiety and depression scale. Acta Psychiatr Scand 1983;67(6):361-370.

21. Aydemir Ö. The validity and reliability study of the Hospital Anxiety and Depression Scale Turkish version. Turk Psikiyatri Derg 1997; 8:280-287. Article in Turkish.

22. Liao D, Higgins M, Bryan NR, Eigenbrodt ML, Chambless LE, Lamar V, et al. Lower pulmonary function and cerebral subclinical abnormalities detected by MRI: the Atherosclerosis Risk in Communities study. Chest 1999;116(1):150-156.

23. Richards M, Strachan D, Hardy R, Kuh D, Wadsworth M. Lung function and cognitive ability in a longitudinal birth cohort study. Psychosom Med 2005;67(4):602-608.

24. Chyou PH, White LR, Yano K, Sharp DS, Burchfiel CM, Chen R, et al. Pulmonary function measures as predictors and correlates of cognitive functioning in later life. Am J Epidemiol 1996;143(8):750-756.

25. Deary IJ, Whalley LJ, Batty GD, Starr JM. Physical fitness and lifetime cognitive change. Neurology 2006;67(7):1195-1200.

26. Etnier J, Johnston R, Dagenbach D, Pollard RJ, Rejeski WJ, Berry $\mathrm{M}$. The relationships among pulmonary function, aerobic fitness, and cognitive functioning in older COPD patients. Chest 1999;116(4): 953-960.

27. Villeneuve S, Pepin V, Rahayel S, Bertrand JA, de Lorimier M, Rizk A, et al. Mild cognitive impairment in moderate to severe COPD: a preliminary study. Chest 2012;142(6):1516-1523.
28. Thakur N, Blanc PD, Julian LJ, Yelin EH, Katz PP, Sidney S, et al COPD and cognitive impairment: the role of hypoxemia and oxygen therapy. Int J Chron Obstruct Pulmon Dis. 2010;5:263-269.

29. Kirkil G, Tug T, Ozel E, Bulut S, Tekatas A, Muz MH. The evaluation of cognitive functions with P300 test for chronic obstructive pulmonary disease patients in attack and stable period. Clin Neurol Neurosurg 2007;109(7):553-560.

30. Grant I, Heaton RK, McSweeny AJ, Adams KM, Timms RM. Neuropsychologic findings in hypoxemic chronic obstructive pulmonary disease. Arch Intern Med 1982;142(8):1470-1476.

31. Antonelli Incalzi R, Marra C, Giordano A, Calcagni ML, Cappa A, Basso S, et al. Cognitive impairment in chronic obstructive pulmonary disease-a neuropsychological and spect study. J Neurol 2003; 250(3):325-332.

32. Tanaka M, Ishii A, Yamano E, Ogikubo H, Okazaki M, Kamimura $\mathrm{K}$, et al. Cognitive dysfunction in elderly females with depressive symptoms. Med Sci Monit 2012;18(12):CR706-CR711.

33. Richard E, Reitz C, Honig LH, Schupf N, Tang MX, Manly JJ, et al. Late-life depression, mild cognitive impairment, and dementia. JAMA Neurol 2013;70(3):374-382.

34. Bunce D, Batterham PJ, Mackinnon AJ, Christensen H. Depression, anxiety and cognition in community-dwelling adults aged 70 years and over. J Psychiatr Res 2012;46(12):1662-1666.

35. Shahnawaz Z, Reppermund S, Brodaty H, Crawford JD, Draper B, Trollor JN, Sachdev PS. Prevalence and characteristics of depression in mild cognitive impairment: the Sydney Memory and Ageing Study. Acta Psychiatr Scand 2013;127(5):394-402.

36. Margari F, Sicolo M, Spinelli L, Mastroianni F, Pastore A, Craig F, Petruzzelli MG. Aggressive behavior, cognitive impairment, and depressive symptoms in elderly subjects. Neuropsychiatr Dis Treat 2012;8:347-353.

37. Gao Y, Huang C, Zhao K, Ma L, Qiu X, Zhang L, et al. Depression as a risk factor for dementia and mild cognitive impairment: a metaanalysis of longitudinal studies. Int J Geriatr Psychiatry 2013;28(5): 441-449.

38. Papazacharias A, Nardini M. The relationship between depression and cognitive deficits. Psychiatr Danub 2012;24(Suppl 1):S179S182. 